\title{
Evolutionary Transitions Among Dinosaurs: Examples from the Jurassic of China
}

\author{
James M. Clark • Xing Xu
}

Published online: 9 May 2009

(C) Springer Science + Business Media, LLC 2009

\begin{abstract}
Dinosaurs have captured the popular imagination more than any other extinct group of organisms and are therefore a powerful tool in teaching evolutionary biology. Most students are familiar with a wide variety of dinosaurs and the relative suddenness of their extinction, but few are aware of the tremendous longevity of their time on Earth and the richness of their fossil record. We first review some of the best-known groups of dinosaurs and discuss how their less-specialized relatives elucidate the path through which each evolved. We then discuss our recent discovery of Yinlong downsi, a distant relative of Triceratops, and other fossils from Jurassic deposits in China to exemplify how the continuing discovery of fossils is filling out the dinosaur family tree.
\end{abstract}

Keywords Dinosaurs · Evolution · Transitional fossils · Mesozoic $\cdot$ China $\cdot$ Jurassic

Dinosaurs need no introduction, they are ubiquitous in popular media as symbols of the terrors of nature and how the mighty fall. But the richness and remarkable duration of the fossil record of dinosaurs are less widely appreciated, and the abundant fossil record of dinosaurs is an excellent example of how fossils provide evidence for evolutionary

\section{J. M. Clark ( $\square)$}

Department of Biological Sciences,

George Washington University,

Washington, DC 20052, USA

e-mail: jclark@gwu.edu

\section{Xu}

Laboratory of Evolutionary Systematics of Vertebrates, Institute of Vertebrate Paleontology and Paleoanthropology,

Chinese Academy of Sciences,

142 Xiwai Street,

Beijing 100044, China relationships and transitions. Familiar highly specialized animals such as Triceratops, Pachycephalosaurus, Stegosaurus, Ankylosaurus, Tyrannosaurus, Brachiosaurus, and Parasaurolophus are joined in the fossil record by hundreds of their relatives with less-specialized features (Weishampel et al. 2004). Together, they comprise a many-branched evolutionary tree that flourished for over 160 million years.

Dinosaurs are found almost exclusively in sedimentary rocks formed in terrestrial, rather than marine, environments, indicating that they rarely ventured out into the sea. These river and lake deposits formed layers, or strata, that are overlain by younger rocks and underlain by older ones. By studying how these and other layers of rocks and their entombed fossils are stacked, scientists called stratigraphers have been able to recognize the sequence in which dinosaurs and other fossils occurred during the Earth's history (Prothero and Schwab 2003). This led to the erection in the early nineteenth century of a timescale with now-familiar names for different time periods, including the Mesozoic Era (popularly called the Age of Dinosaurs) and its three subdivisions, from oldest to youngest, the Triassic, Jurassic, and Cretaceous periods (for a fascinating account of debates in the early nineteenth century over how the time periods were recognized, see Rudwick 1985). However, these divisions reflected only the relative ages of these fossils, and it was not until the last 60 years that ways of estimating the age in years of rocks and fossils were developed. These involve the decay of radioactive elements, which are experimentally shown to occur at rates that take millions or billions of years to complete, depending on the element and isotope.

Radiometric dating comprises a well-developed set of techniques that are now capable of very high resolution (Macdougall 2008). Only relatively young fossils $(<50,000$ years old $)$ can be dated directly, by Carbon- 14 
dating of bone or other carbonaceous fossils, so the dating of dinosaurs millions of years old relies upon dating of the rock layers above, below, and rarely within beds containing fossils. The radioactive decay of isotopes of several different elements (argon, potassium, and uranium) can be used to date dinosaur-bearing rocks because they all have half-lives (the statistically estimated time it would take half of a sample to decay) of the appropriate length, and the use of different isotopes can provide independent checks on any one date.

Radiometric dating estimates the age of a rock at the time that it crystallized, by comparing the amount of "daughter" decay product to the original amount of the radioactive "mother" isotope (calculated as the amount of decay product plus what remains of the mother isotope). Rock layers such as tuffs that formed when volcanic ash, including recently formed tiny crystals, was ejected from a volcano and blanketed the countryside, are ideal for dating. Many tuffs occur in dinosaur-bearing deposits or above or below them, so we have a good idea of how old most dinosaur fossils are (and can estimate all the others).

The oldest dinosaurs, from the Valley of the Moon in Argentina, are dated at $227.8 \pm 0.3$ million years (Rogers et al. 1993; a report of an older dinosaur from Madagascar is being revised), and the extinction event $65.95 \pm 0.04$ million years ago (Kuiper et al. 2008) apparently killed off all of the dinosaurs alive at that time while leaving their descendents, the birds. Dinosaurs were therefore on the Earth for at least 161 million years, and their descendents the birds (reference to Padian contribution) continued on for another 65.95 million years (and thankfully show few signs of leaving us). To put this in perspective, the oldest human fossils are six to seven million years old (Brunet et al. 2002), so the dinosaur fossil record is about 23 to 27 times longer than that of humans.

As with the fossil record in general (Kidwell and Holland 2002), the record of dinosaur fossils is not consistent through time because the deposition of sedimentary rocks in the environments in which dinosaurs lived varied at different times in the Earth's history. This depended both on local conditions and on global phenomena such as plate tectonics and sea level changes, as the mountain building that fueled sedimentation waxed and waned. The incomplete sampling of ancient species by the sedimentary record, coupled with the episodic, greatly incomplete record that was left of those sediments, could not possibly produce a series of forms showing all stages of continuous change from one species to another (whether or not absolutely complete continuity in morphology ever existed is an open question). But some examples of small changes between very similar species over time exist, such as the three successive species of the horned dinosaur Chasmosaurus over approximately 2.5 million years within the Dinosaur Park Formation of Canada (Holmes et al. 2001). More to the point, the periodic sampling of fossils over millions of years is sufficient to provide documentation of the sequential acquisition of specialized features in all of the major dinosaur lineages.

Fossiliferous rocks are more common near the end of the dinosaur's record, at the close of the Cretaceous Period, than in the Jurassic and Triassic, so we know much more about the dinosaurs that lived shortly before they went extinct than those from earlier in their evolution. Nevertheless, the early fossil record of dinosaurs is reasonably well known and includes many complete or nearly complete skeletons. These early fossils are important because older fossils are more likely to include the most basal members of evolutionary lineages, lacking most of the specializations of later forms (we use basal here to refer to members of a group that diverged earlier than other members). These early dinosaurs are generally smaller than their later brethren and have only a few of the features distinguishing the lineage to which they belong. The search for early dinosaurs is among the "hottest" areas of dinosaur research because such dinosaurs are not as common as later ones and hold great potential for elucidating the dinosaurs' early diversification into major evolutionary branches.

A tally of dinosaurs published 3 years ago (Wang and Dodson 2006) recognized 527 genera, the vast majority with only a single species. (Dinosaur paleontologists have a partiality to naming new genera even when a new species is closely related to an existing genus, something our entomological colleagues find mildly disturbing.) For each of these genera, a fossil exists with features that, theoretically, clearly differentiate it from every other known dinosaur genus. For some of these genera, skeletons of many individuals are known (e.g., Protoceratops, Psittacosaurus, Allosaurus, Coelophysis, and Iguanodon), sometimes in the hundreds, and one remarkable bone bed in Alberta, Canada, preserves bones from thousands of individuals of Centrosaurus, a one-horned relative of Triceratops. Wang and Dodson use the known number of dinosaurs and the rate at which new genera are discovered to estimate that 1,850 genera of dinosaurs had existed, in which case less than a third have been discovered.

Evolutionary relationships are evident through the features shared by groups of organisms (Gregory 2008). Just as a very high percentage of human DNA is identical to that of our closest relatives, the chimpanzees, closely related species of all kinds share similar DNA, anatomy, and physiology. One of the main reasons the theory of evolution is accepted is that it provides an explanation for why similar features are found in different organisms. To cite just one example, the presence in all land-living vertebrates of four limbs with digits (reference to Shubin contribution) is explained by the close evolutionary 
relationships of all tetrapods to each other, as members of the same lineages. Supposed alternative theories such as Intelligent Design are mute in explaining these rampant similarities.

Fossil vertebrates - those ancient animals with a bony skeleton - typically preserve only the bones or in rare cases soft tissues such as skin, cartilage, and feathers. DNA is not reliably known from dinosaurs, and recent reports of intact protein (Schweitzer et al. 2007) are intriguing but controversial (Pevzner et al. 2008). Anatomical features of bones such as the peculiar anatomy of the hip that distinguishes all dinosaurs have proven to be extremely useful in understanding dinosaur relationships and show the same hierarchical pattern of nested sets of features that Darwin recognized as reflecting evolutionary relationships. For example, they show that dinosaurs are divided into three distinctive groups - the herbivorous ornithischians such as Triceratops and duck-bills, the huge sauropodomorphs such as Diplodocus, and the generally carnivorous theropods such as Tyrannosaurus rex-and that the sauropodomorphs and theropods are closer to each other than to ornithischians.

Much of paleontological research is devoted to understanding the evolutionary relationships of the species represented in the fossil record. A typical study involves the assembly of a table (data matrix) in which a long list of features are marked as either present or absent for each of the species thought to be closely related to one another based upon previous research or preliminary analysis. For example, a report of a new stegosaur might present a table showing the presence or absence in each known stegosaur species of those features that differ among them. These data are then analyzed using computer algorithms that find the set of evolutionary relationships that most simply explains the features shared by groups of stegosaurs. The result is an estimate of the evolutionary tree of stegosaurs.

\section{The Humble Origins of Some Distinctive Dinosaurs}

The most memorable dinosaurs are those with weird and wonderful features, such as hollow crests, huge horns, giant claws, or bony plates in their skin. These tend to occur in the Late Jurassic and Cretaceous, in the latter half of the Age of Dinosaurs. Many examples of evolutionary transitions are available in the dinosaur fossil record, but here we present some of the more dramatic ones (for more detailed reviews, see Sereno 1999 and Weishampel et al. 2004). This is a greatly simplified account since dinosaur anatomy is complex and comprises hundreds of different features, and dinosaur evolution was of course not a simple march in a single direction but a many-branched tree with many nuances.
Duck-Billed Dinosaurs The duck-billed dinosaurs, or hadrosaurs, were abundant and diverse near the end of the Cretaceous and were among those groups that disappeared at the time of the dinosaur extinction. Their eponymous feature is their bill, a broad area at the front of their mouth that supported a horny bill superficially like that of ducks, but they are distinguished by many other features, including a large number of teeth compressed together to form a grinding surface, and many duck-bills (the lambeosaurines) have crests on their heads with complex hollow passages. The most extreme of these are dinosaurs such as Parasaurolophus, in which the crest extends well beyond the back of the head, and Corythosaurus (Fig. 1b), with a helmet-shaped crest, but others (such as Aralosaurus) have smaller and simpler crests that represent a more primitive condition.

The hadrosaurs of the Late Cretaceous are preceded in the fossil record by a long series of forms that show the incremental acquisition of their specializations, and together with hadrosaurs these forms comprise the group Ornithopoda. The genus Iguanodon of the Early Cretaceous (Fig. 1c, d) is represented by many skeletons and several species, some of which are more closely related to hadrosaurs than are other Iguanodon species (for this reason, most species may not legitimately belong within the genus, and several genera have recently been named to recognize this; Paul 2008). Iguanodon have teeth that are closely packed to form a grinding surface, but there are many fewer teeth than in hadrosaurs. The bill is present, but it is smaller and narrower than that of hadrosaurs. Less specialized still are genera such as Hypsilophodon of the Early Cretaceous (Fig. 1e), which lacks a bill altogether and has teeth that are not closely packed.

Horned Dinosaurs The horned dinosaurs - ceratopsiansare similar to the duck-bills in having a long history that ended with a burst of diversity ending at the Cretaceous extinction event. Triceratops, with its familiar three-horned skull with a long frill on the back, was joined by a variety of close relatives (the other ceratopsids) whose skulls exhibited variations on the theme of horns and frills (Fig. 2a-f)-Pentaceratops, Styracosaurus, and Centrosaurus, among others. The cheek region is flared outward into a pointed structure, ending in an unusual bone called the epijugal. Also like duck-bills, the ceratopsians had very large numbers of closely packed teeth, but they formed a vertical shearing surface rather than a flat grinding surface. Ceratopsians, too, had a beak, but rather than being broad it was vertical and sharp, more like that of a parrot than that of a duck. The anatomy of their forelimbs and backbone indicates that ceratopsians walked on all four legs and could not walk on only two legs.

The specialized ceratopsians with horns and frills- the ceratopsids - are only known in the later part of the Late 
Fig. 1 Ornithopod dinosaurs, showing specialized duck-billed dinosaurs and more primitive species with transitional features. a Skeleton of the hadrosaurid Gryposaurus incurvimanus; $\mathbf{b}$ skeleton of the hadrosaurid Corythosaurus casuarius; c skeleton of Iguanodon bernissartensis; $\mathbf{d}$ skull of Iguanodon bernissartensis; e skull of Hypsilophodon foxii
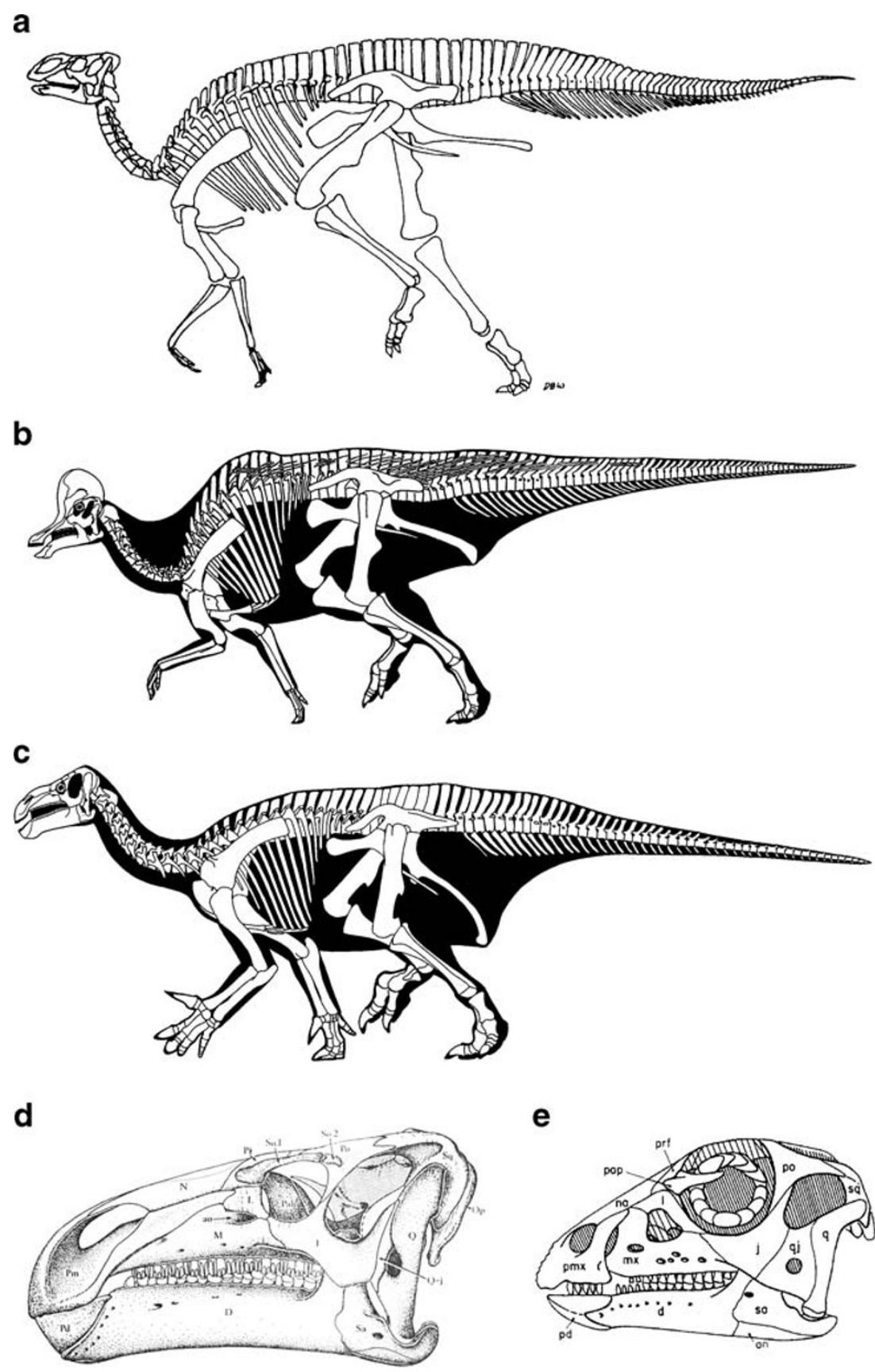

Cretaceous, and more basal ceratopsians mainly from earlier deposits demonstrate the sequence in which these features evolved. Protoceratopsids, which occur in huge numbers in sand dune deposits of the Gobi Desert, have a frill and an epijugal bone and walked on four legs but lack horns (Fig. 2g). Psittacosaurus (Fig. 2h), from the Early Cretaceous, also lacked horns and had only a small frill and a flared cheek without the epijugal bone, and small forelimbs indicate that it walked primarily on its hind legs. The number of teeth and their close packing are reduced in these more basal species.
Sauropods The largest dinosaurs by far-and the largest land animals of all time-are the sauropods such as Brachiosaurus, Diplodocus, and Argentinosaurus. Possibly reaching more than 100 feet $(\sim 30$ meters $)$ in length and weights of over 80 tons (these are difficult to estimate from fragmentary specimens), sauropods are the epitome of large animals. Several groups of sauropods evolved, some with extremely long necks (Mamenchisaurus), some looking like giant giraffes with forelimbs taller than hind limbs (Brachiosaurus; Fig. 3a), and others with long spines 
Fig. 2 Ceratopsian dinosaurs, showing specialized ceratopsids and more primitive species with transitional features. a-f Skulls of ceratopsids: a Centrosaurus apertus; b Einiosaurus procurvicornis; c, e Styracosaurus albertensis; d Achelousaurus horneri; f Pachyrhinosaurus canadensis. g skeleton of Protoceratops andrewsi; $\mathbf{h}$ skeleton of Psittacosaurus mongoliensis a

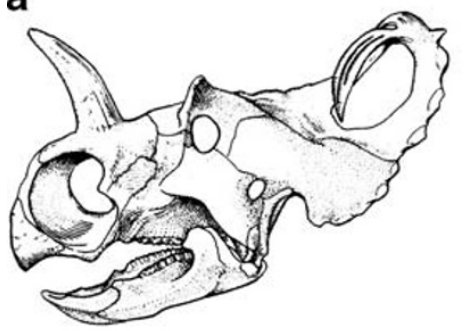

C

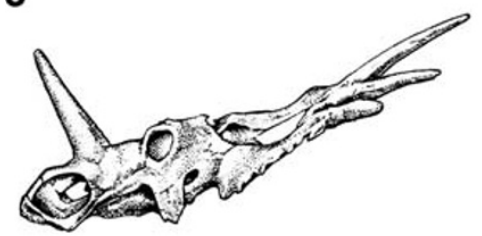

e

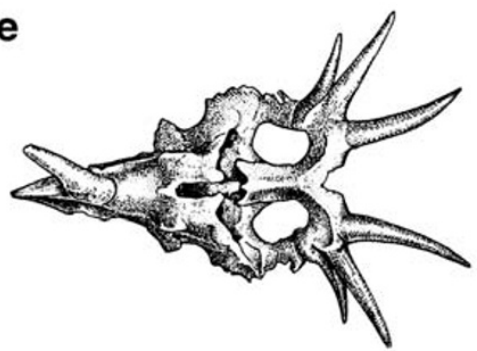

b

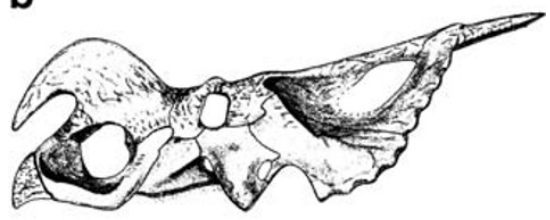

d

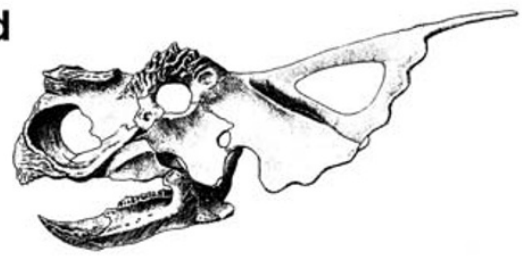

f

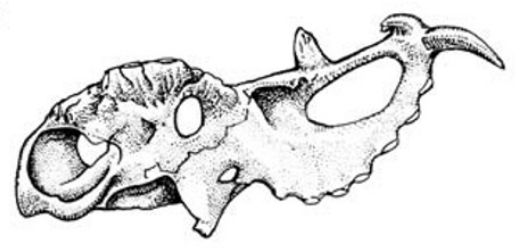

g

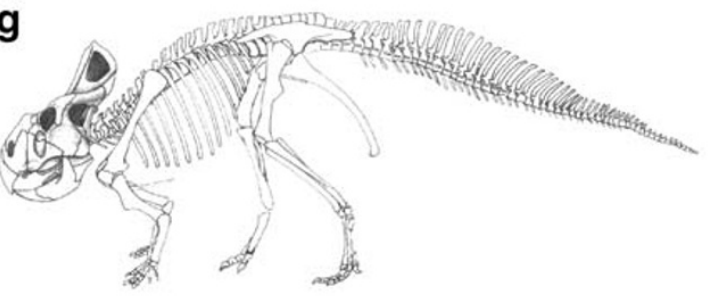

h

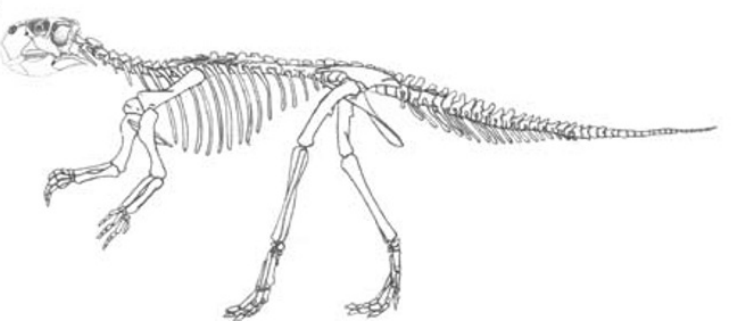

beneath the skin along their neck (dicraeosaurids). Sauropods reached gigantic sizes in the Late Jurassic and lived on until the very end of the Cretaceous.

Sauropods were herbivorous (as indicated by the shape of their teeth), walked on all four limbs and had relatively long necks, and their skeletons have many features related to their large size, such as broad hind feet that spread the weight. Their closest relatives are often called prosauropods and comprise a series of forms that sequentially gained sauropod features. These Late Triassic and Early Jurassic forms include Plateosaurus (Fig. 3b), which had a long neck and plant-eating teeth but walked on its hind legs, and Thecodontosaurus, which had a relatively short neck, walked on its hind legs, and had teeth indicating a more omnivorous diet. Most prosauropods were distinctly smaller than sauropods but were still relatively large, but the oldest and most basal form, Saturnalia, was only about 5 feet (1.5 meters) long.

Ankylosaurs and Stegosaurs The armored dinosaurs, ankylosaurs, and stegosaurs, the best-known members of a group called Thyreophora, all had bony plates that grew in their skin, but each group had its own odd specializations. 
Fig. 3 Examples of a large sauropod and a more basal "prosauropod." a The skeleton of the giant sauropod Brachiosaurus brancai and $\mathbf{b}$ the skeleton of the "prosauropod" Plateosaurus engelhardti

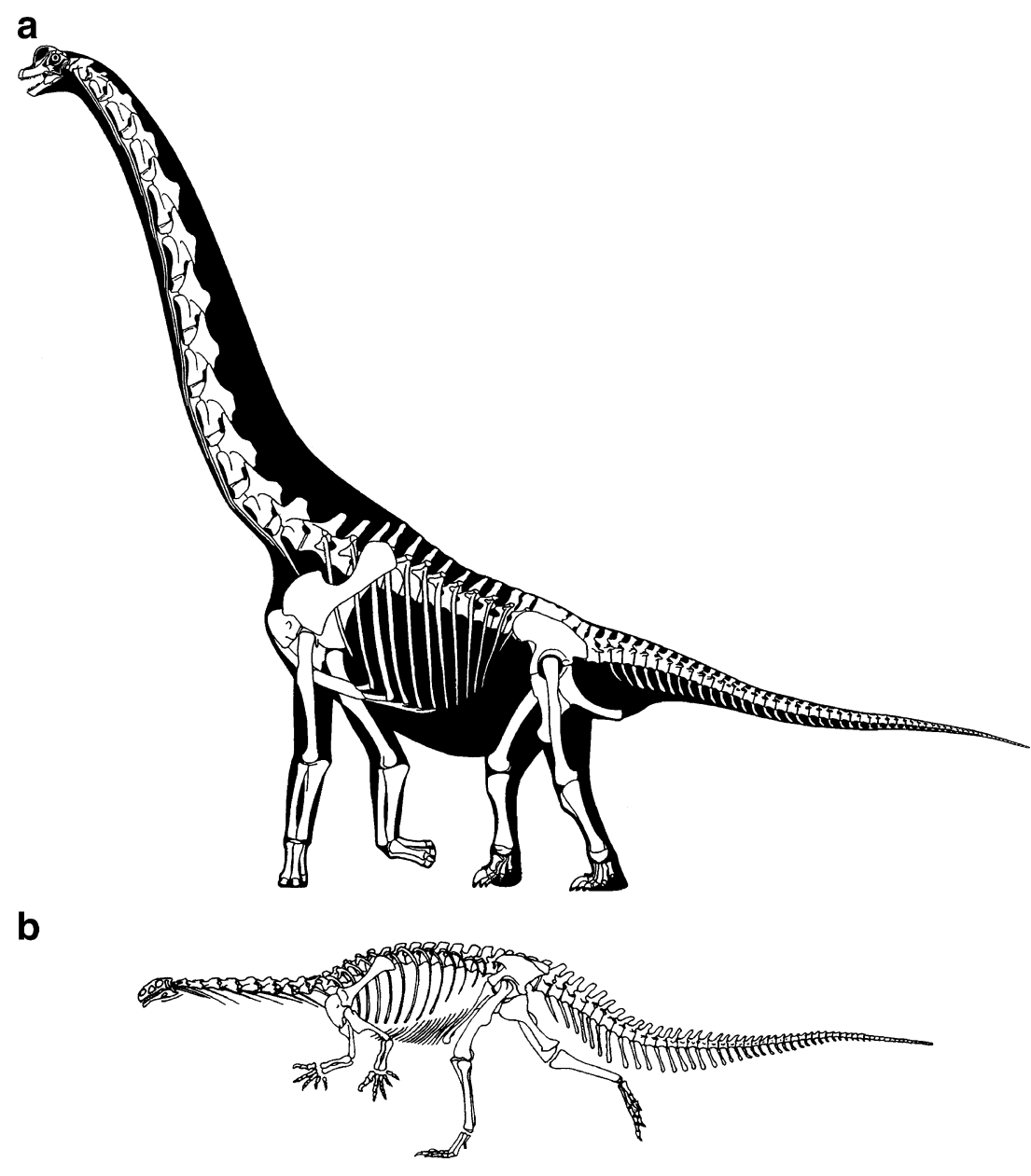

Ankylosaurs (Fig. 4) had thick knobby bones in their skin, and some of them (ankylosaurids) developed a huge bony knob at the end of their tail. Stegosaur plates (Fig. 5a) instead are relatively large and flat and were held outward from the body. Ankylosaur skulls (Fig. 4) are unusually wide and flat on top with large processes and other ornamentation, while stegosaur skulls (Fig. 5b) are unusually narrow and low. Both groups had relatively simple leaf-shaped teeth indicating herbivory and walked on four limbs. They both first appeared in the Middle Jurassic (or possibly the Early Jurassic), and, while the stegosaurs quickly declined after the end of the Jurassic, the ankylosaurs flourished until the very end of the Cretaceous.

The specialized features of stegosaurs, ankylosaurs, and of the entire group Thyreophora were sequentially acquired through a series of more basal forms. The basal stegosaur Huayangosaurus (Fig. 5c) has a wider and taller skull than other stegosaurs, among many other primitive features, and basal ankylosaurs like Cedarpelta and Minmi (Fig. 4c) lack most of the bumps and processes that make the skull of ankylosaurs so strange. Scelidosaurus (Fig. 5d), Emausaurus, and Scutellosaurus from the Early Jurassic are more basal than both ankylosaurs and stegosaurs but like them have bony plates in their skin, though they are simpler. These three forms share a few other features with stegosaurs and ankylosaurs, such as a relatively long body and pelvis, but are decidedly more basal, and the limbs of Scutellosaurus indicate that it walked mainly on its hind legs.

Pachycephalosaurs Among the most bizarre of dinosaurs are the pachycephalosaurs. These Late Cretaceous forms had an incredibly thick skull, forming a dome over the top. The rest of their skeleton was less specialized, and they were relatively small animals by dinosaur standards. The fossil record of the group is very sparse before the end of the Late Cretaceous, but among those forms are some with well-developed domes on their skulls (Fig. 6a, b) and others (Fig. 6c) with a flat skull (recent research shows that we need to be careful that the fossils all represent adults, as domed pachycephalosaur skulls were flat when they were young). The only Early Cretaceous form, Stenopelix, is not known from the skull. Nevertheless, it shows some pachycephalosaur features in its pelvis but not all of them, indicating it is more basal than the Late Cretaceous forms. Finding early basal pachycephalosaurs is one of the goals of many dinosaur paleontologists. 
Fig. 4 Skulls and skeletons of ankylosaurs. a The skull of the ankylosaur Ankylosaurus magniventris from above (left) and left side (right); b the skeleton of the ankylosaur Euoplocephalus tutus; $\mathbf{c}$ the skull of the primitive ankylosaur Minmi paravertebra from above (left) and the right side (right)

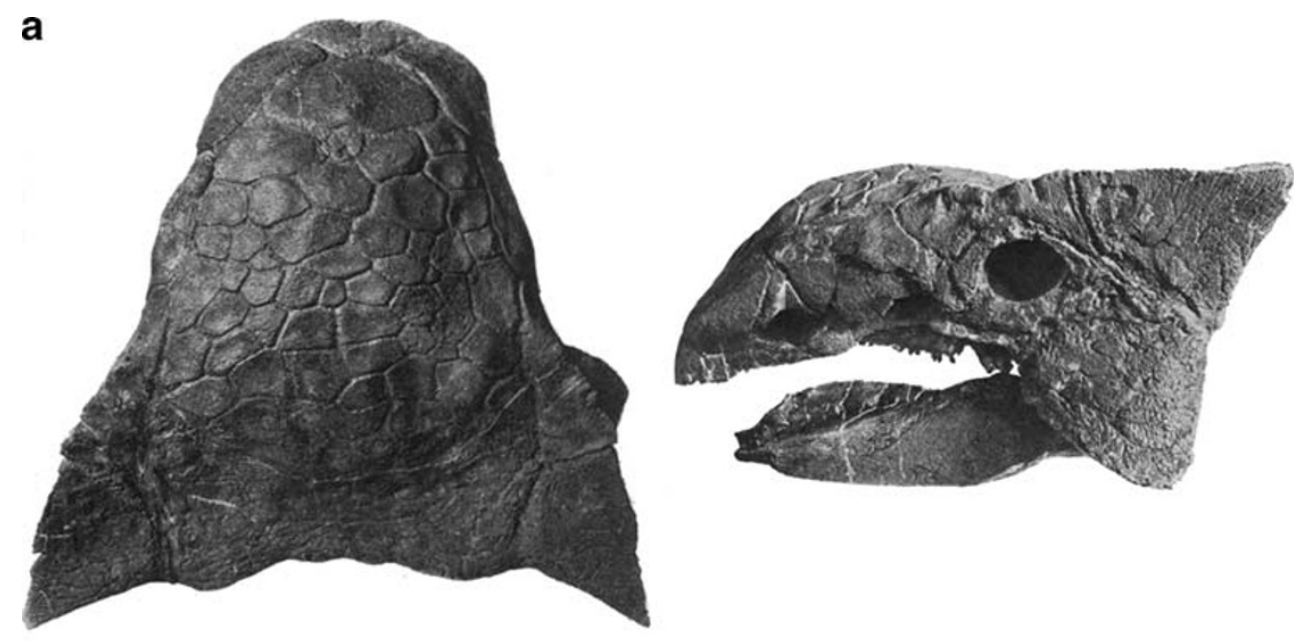

b

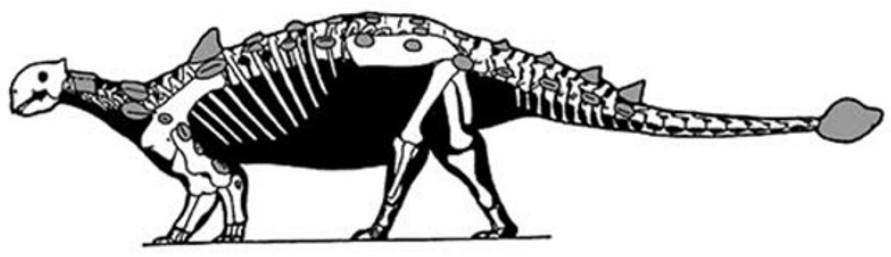

C

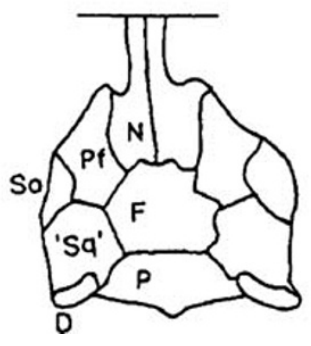

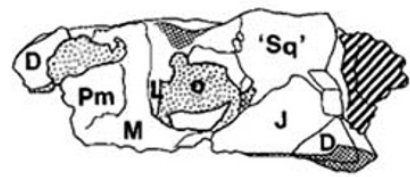

covered with short filamentous feathers ("protofeathers"). This was not entirely surprising, as it was known that tyrannosaurs are closely related to birds, though not as close as are some other theropods. Feathers probably occurred in other tyrannosaurs, but only rarely are conditions in the fossil record ideal for preserving soft tissues such as these.

Therizinosaurs We end this review with a group of poorly known dinosaurs that are favorites of ours, the therizinosaurs, also called segnosaurs. Therizinosaurs are strange animals that combine features of disparate groups of dinosaurs, including the teeth of ornithischians, the skulls and feet of prosauropods, and the hands of theropods. The first to be discovered, Therizinosaurus, had huge flat claws superficially similar to those of turtles, so that it was initially allied with them. The relationships of these Late Cretaceous forms were hotly debated, but recent discoveries have sorted out the features they share with other dinosaurs and shown decisively that they are theropods and among the group of theropods that are closely related to birds. 
Fig. 5 Stegosaurs and close relatives of stegosaurs and ankylosaurs. a The skeleton of Stegosaurus stenops; b the skull of $S$. stenops from the left side; c the skull of the primitive stegosaur Huayangosaurus taibaii; $\mathbf{d}$ the skeleton of the stegosaur and ankylosaur relative Scelidosaurus harrisonii
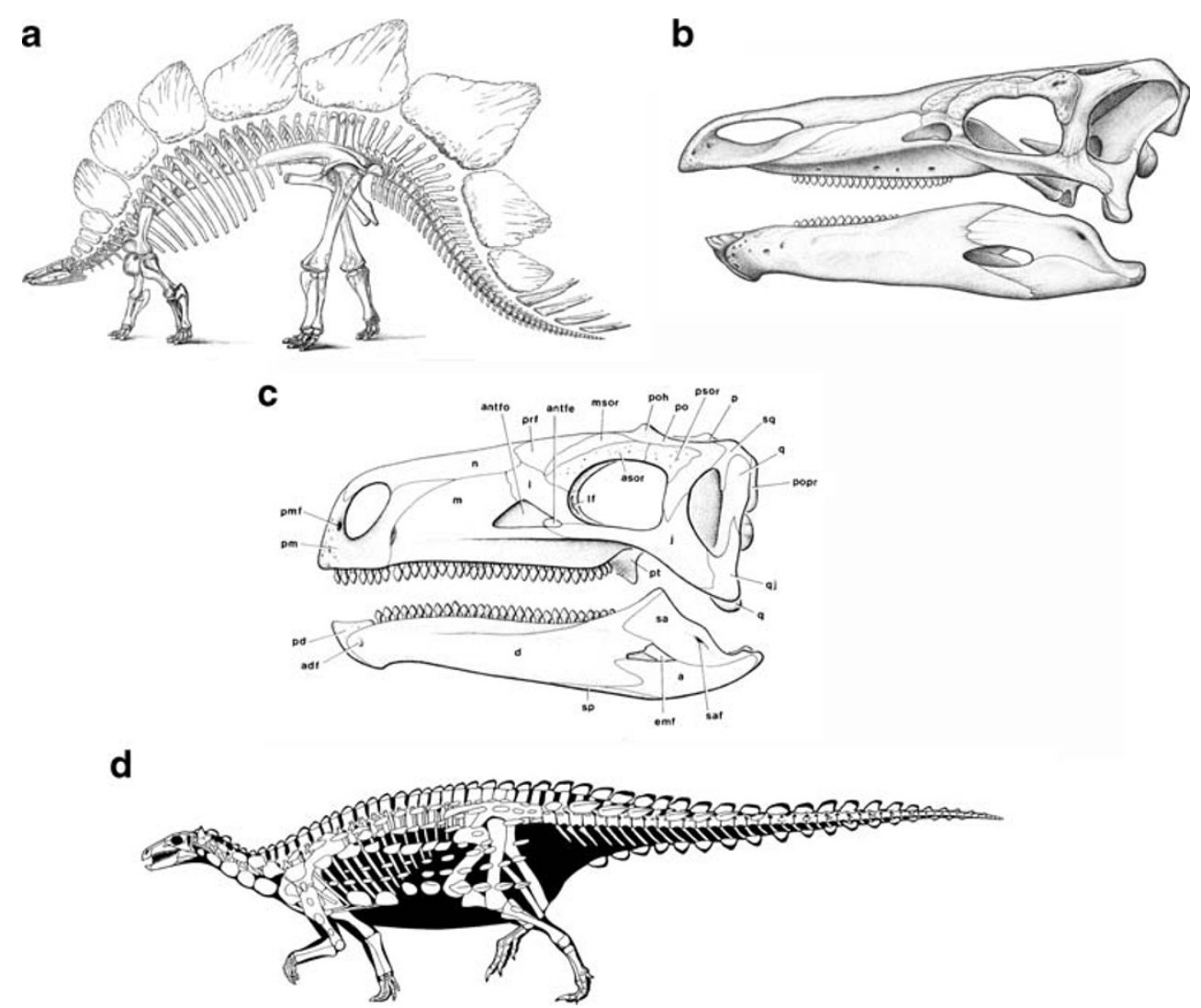

The first of these discoveries was Beipiaosaurus, from the Early Cretaceous of China (Xu et al. 1999), which showed that basal therizinosaurs had a three-toed foot like theropods, and the four-toed prosauropod-like foot evolved later in therizinosaurs independent of prosauropods. Beipiaosaurus also was preserved with filamentous feathers, like those of the tyrannosaur Dilong. More recently, an even more basal therizinosaur was discovered in the Early Cretaceous of Utah, Falcarius (Kirkland et al. 2005), which mainly has primitive features but also a few distinctive therizinosaur features (Fig. 8b). It has leaf-like teeth and a broad pelvis like other therizinosaurs, interpreted to be indicative of an herbivorous diet (the broad pelvis is thought to indicate a relatively large stomach, as in living herbivorous mammals). But unlike all other therizinosaurs Falcarius lacks a distinctive ridge on its lower jaw; its pelvis is not as specialized, and its foot is even more like that of other theropods than is that of Beipiaosaurus.

\section{Our Search for Early Dinosaurs in the Gobi Desert of China}

The search for new dinosaurs is an ongoing effort involving hundreds of paleontologists. Our own recent efforts targeted fossil deposits in northwestern China, in the Junggar Basin west of Mongolia. This region is in the westernmost part of the Gobi Desert, a desert renowned for its rich fossil beds. We chose the Junggar Basin because earlier exploration of the sediments here by Chinese and Canadian paleontologists discovered intriguing fossils from a poorly known time period critical to understanding the evolution of dinosaurs.

After the origin of dinosaurs in the Triassic Period, they diversified and first reached immense sizes in the Jurassic Period. The dinosaurs of the Early Jurassic are large by modern standards (some were larger than elephants) but relatively small compared to the giants of the Late Jurassic and Cretaceous. Although the three major dinosaur groups (ornithischians, sauropodomorphs, and theropods) were already present, many of the distinctive lineages within each did not appear until later. Surprisingly, Early Jurassic dinosaurs from around the world are very similar, a reflection of the geographic continuity between all of the continents, which were then part of the single supercontinent of Pangaea. The diversification and enlargement of dinosaurs later in the Jurassic corresponded with the earliest splitting of Pangaea, marked by the opening of the Atlantic Ocean, which ultimately resulted in the continental configurations we know today.

One of the most poorly known time periods in the history of dinosaurs is the middle part of the Jurassic. It was 
Fig. 6 Pachycephalosaurs. a Skull of the domed pachycephalosaur Prenocephale prenes; b skull of the domed pachycephalosaur Stegoceras validum; c skull of the domeless pachycephalosaur Homalocephale calathocercos from the left side (left) and above (right)
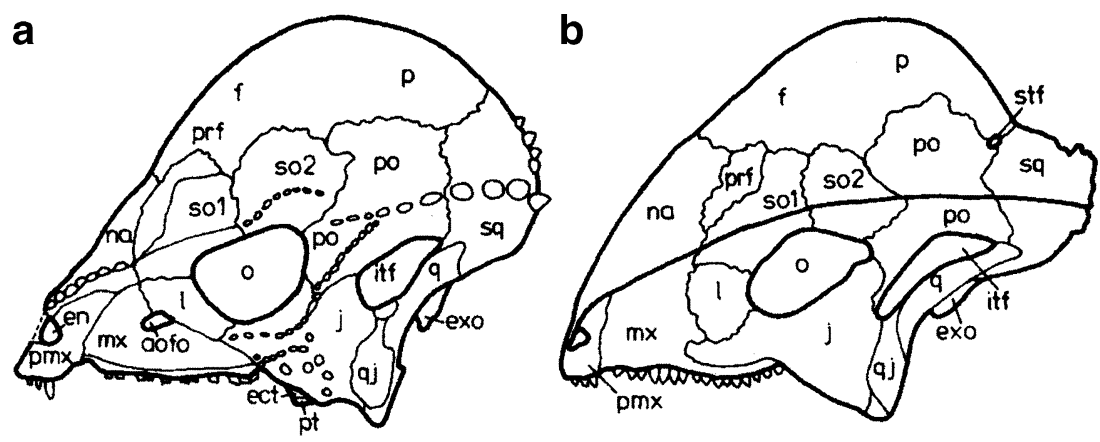

C
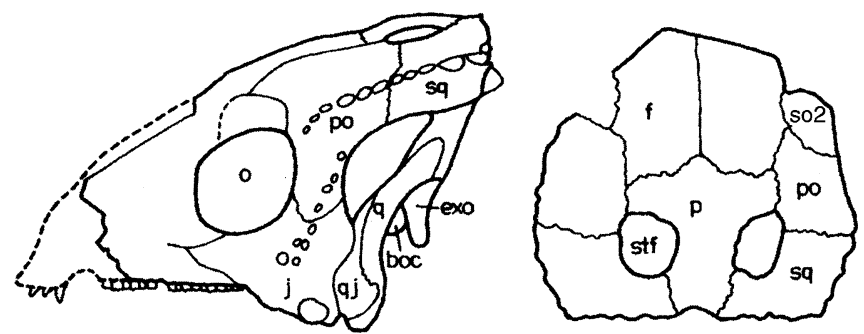

during this period that many distinctive groups of dinosaurs, including the first gigantic ones, appeared. Only three areas in the world are known to have fossil beds with relatively abundant dinosaur skeletons at this time, and two of them are in China (the other is in the Patagonian region of Argentina). The first to be discovered is in the southern Chinese province of Szechuan, near the city of Zigong. Rich fossil beds densely packed with dinosaur skeletons occur here, and there is a spectacular display of in situ skeletons at a museum that should be on every dinosaur fan's agenda should they tour China.

We chose to concentrate our efforts in another area of China, the Shishugou Formation in the Xinjiang Autonomous Region near where the ancient Silk Road once passed. Based upon previous discoveries there, such as the theropod dinosaur Sinraptor and the sauropod dinosaur Bellusaurus, we reasoned that an immense area that had not been explored must preserve many more fossils. For six summers, from 2001 to 2006, we assembled a large group of scientists, technicians, students, and local workers to camp out in the badlands and comb the area for fossils.

The Shishugou Formation was named for the many petrified tree trunks found in some areas, some of which are preserved standing upright; Shi Shu Gou translates as "rock tree gully." A formation is a formally named geological feature that comprises a thick relatively homogeneous set of strata occurring over an area large enough to map. Geological mapping of the area, along with satellite photographs, allowed us to pinpoint the areas that these rocks were exposed in and could be examined for fossils (many formations are covered by plants or soil, which makes finding fossils in them difficult or impossible). During our first year, we discovered that the best area for fossils was a set of badlands in an area called Wucaiwan (Fig. 9), some of which were featured in the film "Crouching Tiger, Hidden Dragon."
Fig. 7 T. rex and a more basal tyrannosaur. a Skeleton of the gigantic tyrannosaurid T. rex; b skeleton of the basal tyrannosaur Dilong paradoxus

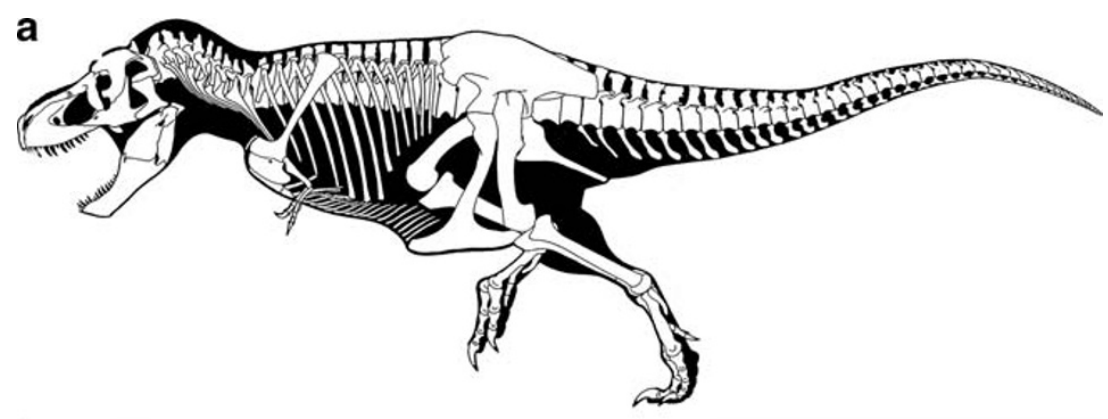

b

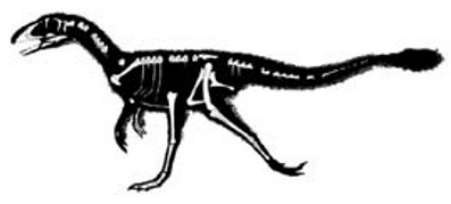


Fig. 8 The strange therizinosaur theropods. a Skeleton of the therizinosaur Nanshiungosaurus brevispinus (known only from forelimbs, the remainder of the reconstruction is apparently based upon Nanshiungosaurus brevispinus); $\mathbf{b}$ the skeleton of the basal therizinosaur Falcarius utahensis

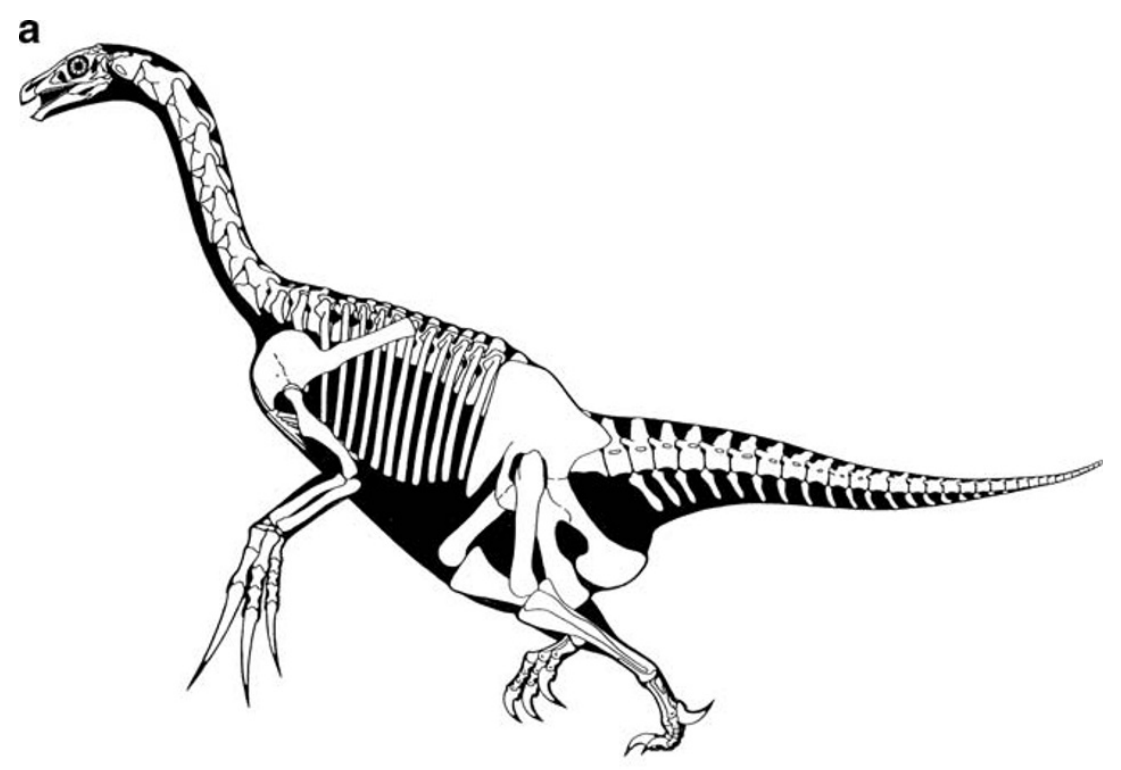

b

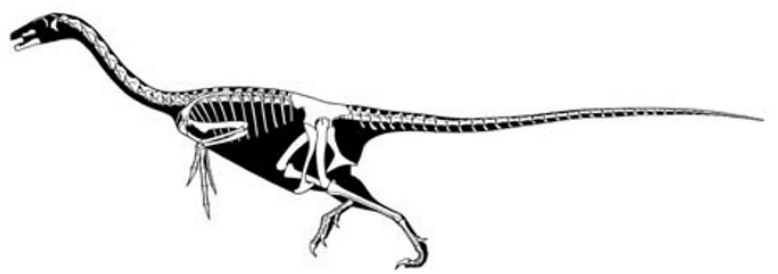

Wucaiwan proved to be a treasure trove of fossils, and curiously they are predominately small, with very few large fossils. This is in many ways fortunate because smaller fossils are easier to excavate than huge skeletons, and a greater number and diversity can be collected in a short time. Huge fossils are preserved at Wucaiwan, such as the occasional sauropod vertebra or leg bone we encountered, but for reasons having to do with how the sediments were being deposited we found no intact large skeletons.

One of the first things we did was to collect samples of tuffs for dating. Fortunately, tuffs occur at several levels in the formation, so we could bracket most of the fossil occurrences between these dated tuffs. Radiometric dating of these tuffs showed that the rocks forming the Shishugou Formation at Wucaiwan were first deposited near the end of the Middle Jurassic and continued into the early part of the Late Jurassic about 159 million years ago.

We discovered at least seven new species of dinosaurs at Wucaiwan, mostly theropods. This is odd because theropods, which were generally carnivores, are relatively rare in the fossils record, as are carnivores in modern ecosystems. One of the reasons for the abundance of theropods at Wucaiwan is that many of the theropods we collected had been trapped in mud pits, small areas of watery sticky mud that the theropods were unable to extricate themselves from. These "death traps" were the subject of a TV documentary by National Geographic and an article in National Geographic Magazine (Gwin 2008). The skeletons in these pits are predominately those of theropods, a highly unusual occurrence. We surmise that the theropods' long gracile legs and, in some cases, weak arms, made them more vulnerable than other animals to the sticky mud.

The first dinosaur we described from Wucaiwan was a theropod dinosaur preserved at the top of a stack of five dinosaurs in one of these mud traps. An adult and a juvenile were preserved (Fig. 10a, b), to which we gave the name Guanlong (crested dragon), as the adult bore a large thin crest along the top of its head (Xu et al. 2006a, b). Our study of the homologies in the skeleton of Guanlong led us to the conclusion that it was the oldest and most primitive tyrannosaur, the group including T. rex. But it is so primitive (even more primitive than Dilong) that most of the distinctive features of T. rex had not yet appeared, and only a few relatively subtle traits in its skull and pelvis point to its tyrannosaur affinities; for example, it has teeth at the front of its mouth with a "D"-shaped cross section, and its main pelvic bone (the ilium) has a distinctive ridge running up and down its blade. Its skull and arms are decidedly more primitive than those of $T$. rex, the skull being long and low and the arms long and well developed. The crest on its head is an interesting attribute that may say something about the biology of early tyrannosaurs (such 


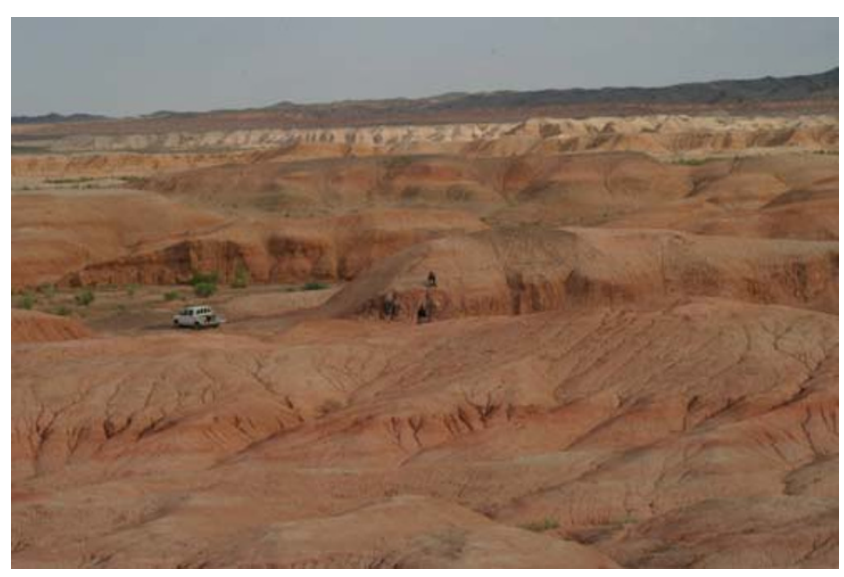

Fig. 9 Outcrops of the Middle to Late Jurassic Shishugou Formation at Wucaiwan, Xinjiang

crests may reflect visual displays involved in mating), and small ridges on the top of the skull of Dilong support the idea that similar crests were widespread in early tyrannosaurs and then lost in later forms.

The herbivorous dinosaurs that likely formed the bulk of Guanlong's diet include an ornithopod (duck-bill relative) and a ceratopsian (Triceratops relative). Some of the problems paleontologists face are that the first fossil found of a species may be very fragmentary and that these specimens may be lost; both of these are the case with the Wucaiwan ornithopod. Gongbusaurus wucaiwanensis was described in 1989 based on fragmentary fossils, but these can no longer be found in the collections to which they belong. We now have several complete skeletons (Fig. 11) of an ornithopod that is probably this species, which is more primitive than Hypsilophodon, but we are still trying to figure out whether the old name can be used. It appears to be one of the oldest and most primitive ornithopods, but this needs more study. Several species thought to be basal ornithopods occur in older beds, but there are so few differences between basal ornithopods and even more basal ornithischians that it is unclear exactly where the ornithopod line started.

One of the most important and revealing discoveries we made at Wucaiwan was the ceratopsian Yinlong (from the Chinese words for "hidden dragon," a homage to the movie filmed nearby). Yinlong (Fig. 10c) is clearly a ceratopsian because it shares several distinctive features with them including a bone at the end of its nose found only in ceratopsians (the rostral bone). But it is extremely primitive, more so than any other known ceratopsian, as might be expected since it is also the oldest known ceratopsian. Its limbs indicate that it walked on its hind limbs rather than on all four legs; there is almost no frill behind its head; there is little flaring of the cheek; the teeth are not compressed together, and the rostral bone is much smaller than in all other ceratopsians. More surprising is that, in addition to the features it shares with ceratopsians, it also possesses a few features that previously were known only in pachycephalosaurs.

Paleontologists suspected that ceratopsians and pachycephalosaurs were related, so they were placed together in a group called Marginocephalia, named for the presence in both of a bony outgrowth around the back margin of the skull. What Yinlong shows is that early ceratopsians shared several features with pachycephalosaurs that were retained from the common ancestor of both groups. The skull of pachycephalosaurs is distinguished mainly by bony outgrowths along the edge and the top of the skull. Some of these are seen in Yinlong, in which the edges around the top of the skull, behind the eye sockets, and on the lower jaw have rough areas in the same positions as the bony outgrowths of pachycephalosaurs. These and a few other features considerably strengthen the evidence that ceratopsians and pachycephalosaurs, two of the most specialized

\section{a}

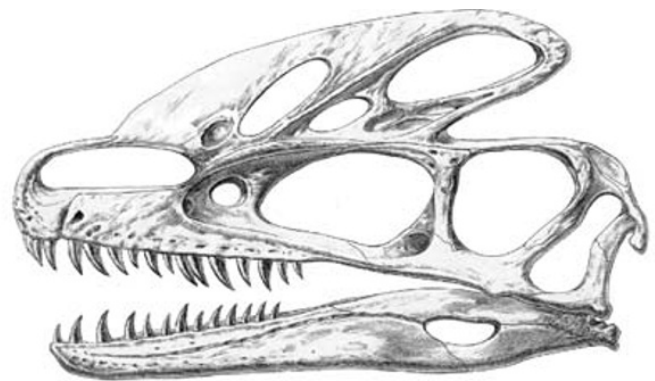

b

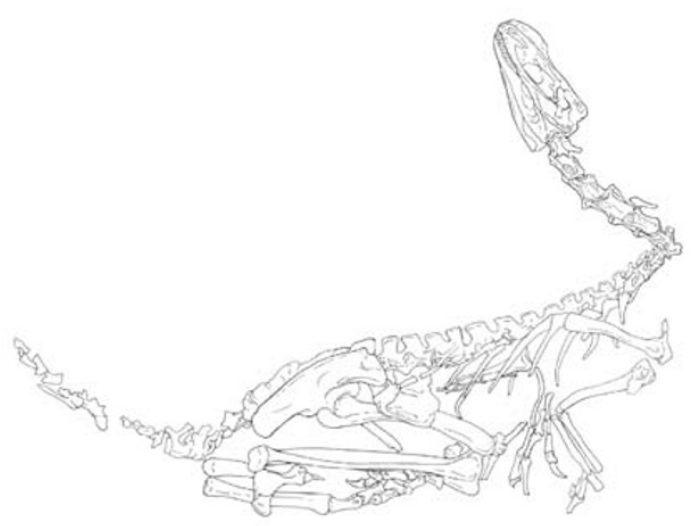

C
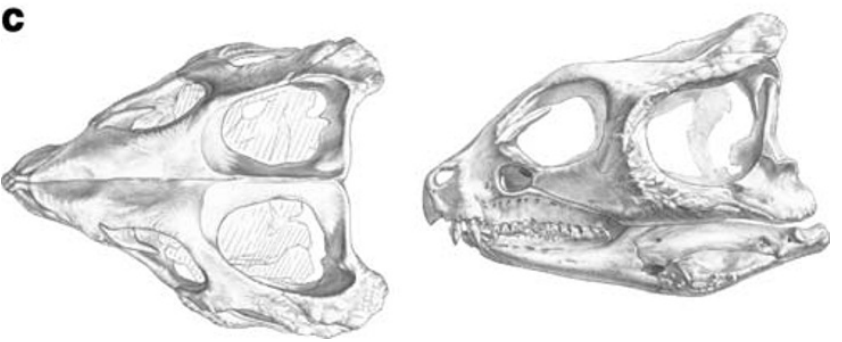

Fig. 10 New dinosaurs from Wucaiwan. a The skull of the basal tyrannosaur Guanlong wucaii; b skeleton of Guanlong wucaii (the crest on the skull of this specimens is broken off); c skull of the basal ceratopsian Yinlong downsi, from above (left) and the left side (right) 
Fig. 11 Skeleton of a basal ornithopod from Wucaiwan, similar to G. wucaiwanensis

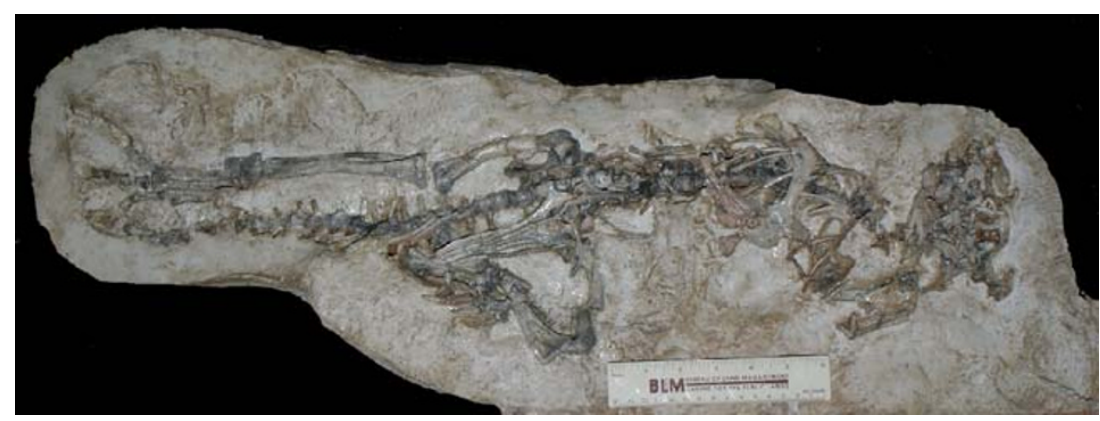

groups of dinosaurs, shared a common ancestor in the Jurassic.

The Wucaiwan fossils continue to shed light on the early evolution of dinosaurs, and many we collected have not yet been studied. Already, they include primitive members of three of the major groups of dinosaurs that flourished near the end of the Cretaceous - the ceratopsians, duck-bills, and tyrannosaurs - at least two of which are the oldest representatives of their groups. Ongoing studies of these fossils promise to shed light on the early evolution of several groups of dinosaurs, especially the theropods closely related to birds.

Acknowledgments Support for this project was provided by the National Geographic Society, the National Natural Science Foundation of China, and the US National Science Foundation.

Images provided by permission of G.S. Paul (1b,c, 3a, 5d, 7a, 8a, b), K. Carpenter (4b), American Museum of Natural History (2g,h), D. Nicholls (1a), D. Norman (1d), T. Maryanska and Palaeontologia Polonica (6), P. Sereno and J. Vert. Paleo. (5b,c), S. Sampson and J. Vert. Paleo. (2b,d), R. Molnar and the Queensland Museum (4c), Yale Peabody Museum (2a,c,e,f), P. Galton (1e, 3b), Nature (7b, 10a,b), and Royal Soc. London (10c).

\section{References}

Brunet M, et al. A new hominid from the Upper Miocene of Chad, Central Africa. Nature. 2002;418:145-51. doi:10.1038/ nature00879.

Gregory TR. Understanding evolutionary trees. Evo Edu Outreach. 2008; $1: 127-37$.

Gwin P. The real Jurassic park. Nat Geog. 2008;214:104-15.

Holmes R, Forster C, Ryan M, Shepherd K. A new species of Chasmosaurus (Dinosauria: Ceratopsia) from the Dinosaur Park Formation of southern Alberta. Can J Earth Sci. 2001;38:142338. doi:10.1139/cjes-38-10-1423.

Kidwell SM, Holland SM. The quality of the fossil record. Annu Rev Ecol Syst. 2002;33:561-88. doi:10.1146/annurev. ecolsys.33.030602.152151.
Kirkland JI, Zanno LE, Sampson SD, Clark JM, DeBlieux DD. A primitive therizinosauroid dinosaur from the early Cretaceous of Utah. Nature. 2005;435:84-7. doi:10.1038/nature03468.

Kuiper KF, Deino A, Hilgen FJ, Krijgsman W, Renne PR, Wijbrans JR. Synchronizing rock clocks of Earth history. Science. 2008;320:500-4. doi:10.1126/science.1154339.

Macdougall D. Nature's clocks: how scientists measure the age of almost everything. Berkeley: University of California Press; 2008. p. 271.

Paul GS. A revised taxonomy of the iguanodont dinosaur genera and species. Cretac Res. 2008;29:192-216.

Pevzner PA, Kim S, Ng J. Comment on "protein sequences from Mastodon and Tyrannosaurus rex revealed by mass spectrometry". Science. 2008;321(5892):1040. doi:10.1126/science.1155006.

Prothero D, Schwab F. Sedimentary geology. 2nd ed. New York: Freeman; 2003. p. 600.

Rogers RR, Swisher CC III, Sereno PC, Monetta AM, Forster CA, Martínez RN. The Ischigualasto tetrapod assemblage (Late Triassic, Argentina) and 40Ar/39Ar dating of dinosaur origins. Science. 1993;260:794-7. doi:10.1126/science.260.5109.794.

Rudwick MJS. The great Devonian controversy. Chicago: University of Chicago Press; 1985. p. 494.

Schweitzer MH, Suo Z, Avci R, Asara JM, Allen MA, Arce FT, et al. Analyses of soft tissue from Tyrannosaurus rex suggest the presence of protein. Science. 2007;316:277-80. doi:10.1126/science.1138709.

Sereno PC. The evolution of dinosaurs. Science. 1999;284:2137-47. doi:10.1126/science.284.5423.2137.

Wang SC, Dodson P. Estimating the diversity of dinosaurs. Proc Natl Acad Sci U S A. 2006;103:13601-5. doi:10.1073/pnas.0606028103.

Weishampel D, Dodson P, Osmólska H. The Dinosauria. 2nd ed. Berkeley: University of California Press; 2004. p. 861.

$\mathrm{Xu} \mathrm{X}$, Tang ZL, Wang XL. A therizinosauroid dinosaur with integumentary structures from China. Nature. 1999;399:350-4. doi: $10.1038 / 20670$.

Xu X, Norell M, Kuang X, Wang X, Zhao Q, Jia C. Basal tyrannosauroids from China and evidence for protofeathers in tyrannosauroids. Nature. 2004;431:680-4. doi:10.1038/nature02855.

Xu X, Clark JM, Forster CA, Norell MA, Erickson GM, Eberth DA, et al. A basal tyrannosauroid dinosaur from the Late Jurassic of China. Nature. 2006a;439:715-8. doi:10.1038/nature04511.

$\mathrm{Xu} \mathrm{X,} \mathrm{Forster} \mathrm{CA,} \mathrm{Clark} \mathrm{JM,} \mathrm{Mo} \mathrm{J.} \mathrm{A} \mathrm{basal} \mathrm{ceratopsian} \mathrm{with}$ transitional features from the Late Jurassic of northwestern China. Proc R Soc Lond B Biol Sci. 2006b;273:2135-40. doi:10.1098/rspb.2006.3566. 